\title{
Let there be light
}

\author{
The 2018 Nobel Prize in Physics has been awarded for advances in laser physics that have conferred a formidable \\ benefit to humankind - on both fundamental and applied fronts.
}

$\Lambda$ $\mathrm{t}$ first glance, the advances named in this year's Nobel Prize "for groundbreaking inventions in the field of laser physics" are rather tenuously linked. The award could be cast lazily as belated credit for an overlooked collaborator, a nod toward gender diversity - or even indirect praise for interdisciplinary research. But a closer look reveals two discoveries that have shaped entire fields of research, in some cases making improvements to countless lives.

Half of the prize has been awarded to Arthur Ashkin for his invention of optical tweezers, and his part in their becoming one of the most powerful tools for single-molecule approaches to biology. Gérard Mourou and Donna Strickland share the other half for inventing chirped pulse amplification as a means of generating high-intensity ultrashort optical pulses.

In terms of reach, both techniques boast extraordinary influence. Chirped pulse amplification - a way of stretching, amplifying and compressing light - has replaced almost all previous variants for ultrashort pulse generation at high intensities. The method has made possible myriad laser-based spectroscopic techniques, made visible processes that would otherwise be deemed instantaneous, and has kick-started new approaches to precision cutting. But perhaps its most wellknown benefactors are ophthalmologists: corrective laser eye surgery would still be the stuff of science fiction had Strickland and Mourou not hit upon the technique.

The impact of optical tweezers is no less impressive, although it has yet to make it out of the laboratory. Ashkin's genius was in realizing shortly after the laser's invention in 1960 that it might be used to move small things around - in fact, what he found was that the variation in radiation pressure across a laser beam could be exploited to hold things in place. Perhaps more surprising was his revelation that certain types of laser could even trap living things without killing them. And so began the age of single-molecule biology using optical tweezers.
Biophysicist Michael Woodside is philosophical in his praise for Ashkin's discovery. "Optical tweezers played a significant role in broadening the application of physics and physical concepts into the life sciences," he says, explaining that these new types of measurement and new ways of manipulating living systems necessarily sparked an update to the way people had been thinking about biological problems. Stephan Grill notes that whereas X-ray crystallography had previously given us the false impression that proteins are rigid structures, optical tweezers brought us "the understanding that proteins are molecular machines that can perform mechanical work against opposing forces."

\section{A closer look reveals two discoveries that have shaped entire fields of research, in some cases making improve- ments to countless lives.}

But biophysicists haven't been the only scientists to profit from the power of optical tweezers. Chris Jarzynski recalls the early scepticism with which fluctuation theorems were met in the non-equilibrium physics community. Optical tweezers provided the much-needed empirical confirmation ${ }^{1,2}$ to make the theorems, as one detractor complained, 'physical reality'. "I don't think Arthur Ashkin had the second law of thermodynamics in mind when he demonstrated optical tweezers," muses Jarzynski, "but his invention ultimately provided decisive tests of theoretical predictions about how the second law 'scales down' to very small systems."

Within the vast community of scientists using optical tweezers, there is a sense that Ashkin's award is overdue. He himself has been known to grumble about missing out when Steven Chu won the prize for laser cooling in $1997^{3}$. Both at Bell Labs, Ashkin convinced a newly recruited Chu to help him realize an optical trap. Together they published their findings in $1985^{4}$, and Ashkin's optical tweezers followed two years later, after he realized that he could use light to manipulate living bacteria and viruses without causing them harm ${ }^{5}$. In the fanfare that accompanied the 1997 award, Ashkin took umbrage when he was mistakenly cast as a member of Chu's lab by co-winner William Phillips.

Of course, deciding who makes the final cut for the Nobel in this era of large- and small-scale collaborations will always be a contentious issue. Much has been made of the fact that Strickland is only the third woman ever to have won the prize for physics - and that more than half a century has passed since her predecessor Maria Goeppert Mayer accepted the award. Rosalind Franklin is perhaps the most famous example of female collateral in the male-dominated Nobel history, but countless other collaborators have no doubt been overlooked on the basis of gender bias.

A subtler prejudice seems to exist when it comes to recognizing milestones that cross disciplinary boundaries. Indeed, according to the data analysis reported in the Perspective by Roberta Sinatra and colleagues in this issue, few Nobel Prizes have been awarded for interdisciplinary achievements - particularly those on the interface between physics and the life sciences. One can only hope that this year's prize heralds a new attitude towards the status quo.

Published online: 1 November 2018 https://doi.org/10.1038/s41567-018-0349-8

\footnotetext{
References

1. Liphardt, J., Dumont, S., Smith, S. B., Tinoco, I. Jr \& Bustamante, C. Science 296, 1832-1835 (2002).

2. Wang, G. M., Sevick, E. M., Mittag, E., Searles, D. J. \& Evans, D. Phys. Rev. Lett. 89, 050601 (2002)

3. Shenkenberg, D. L. Photonics Media https://www.photonics.com/ article. aspx?aid=36444 (2009).

4. Chu, S., Hollberg, L., Bjorkholm, J. E., Cable, A. \& Ashkin, A. Phys. Rev. Lett. 55, 48-51 (1985).

5. Ashkin, A. \& Dziedzic, J. M. Science 235, 1517-1520 (1987).
} 